\title{
Boundaries Crossed and Boundaries Made: The Productive Tension Between Learning and Influence in Transformative Networks
}

\author{
Julie Risien $^{1}$ D $\cdot$ Bruce Evan Goldstein ${ }^{2}$ (DD
}

Accepted: 27 March 2021 / Published online: 19 April 2021

(C) The Author(s) 2021

\begin{abstract}
We present an in-depth case study of a learning network that aims to transform infrastructure and practice across the research enterprise to advance societal impacts. The theory of social morphogenesis guides our processual qualitative analysis of the network. We describe how different types of boundary work, both building and navigating across boundaries, operate in tension while contributing to transformative capacity. We conclude that learning networks can play a robust role in fostering transformation by drawing together and holding together forces which expand knowledge and authority over time iteratively and recursively. In addition to this theoretical contribution, we provide practical guidance for how network leaders can dynamically manage boundaries, shifting emphasis between strength and fluidity to support transformative change across sites and scales.
\end{abstract}

Keywords Boundary work $\cdot$ Learning network $\cdot$ Morphogenesis $\cdot$ Structuration · Transformation $\cdot$ Transformative capacity $\cdot$ Societal impacts of research

\section{Introduction}

Learning networks offer the academic community a way to address the critical challenge of broadening the impact of the research enterprise to meet societal needs and the increasingly complex requirements of funding agencies. Effectively used to improve higher education STEM instructional practices (Hill et al. 2019; Beach

Julie Risien

Julie.Risien@oregonstate.edu

1 STEM Research Center and Environmental Sciences Graduate Program, Oregon State University, 254 Gilbert Hall, Corvallis, OR 97331, USA

2 Environmental Design Program, University of Colorado Boulder, Boulder, CO, USA 
et al. 2016; Kezar 2014; Kezar and Gehrke 2015), networked approaches to transformation vary in structure and design but share a common purpose to work across institutional contexts, bringing together diverse capacities and points of view to enable learning and stimulate transformation of practice and norms in higher education. Here we aim to show, through deep and processual analysis of a single case, how a network can progressively build transformative capacity to both innovate practice and influence policy. Our results, presented as a theoretical contribution, bridge core social theory about structure and agency with the study of networks to enable application in network practice. Our conclusions align with recent studies of transformative learning networks that show a flexible and light structure, with emphasis on dynamic and adaptive principles, enables transformative capacity by optimizing interactions across sites and scales (Goldstein et al. 2017b).

This work can contribute to the developing discourse on translocal empowerment through networks (Avelino et al. 2020) and builds on recent efforts to develop transformative social innovation theory that is grounded in practice and attends to system complexity. Haxeltine and others defined transformative social innovation as "a process of changing social relations that involves the emergence and spread of new knowledge and practices that challenge, alter or replace the established institutions in a specific context" (2017: 61). We apply the concept of transformative potential, which builds on transformative social innovation theory by highlighting the ways in which "socially innovative relations" and "ways of doing, organizing, framing, and knowing" challenge, alter, or replace institutional norms (Strasser et al. 2019: 7). In their framework of network leadership, Strasser and others understand transformative capacity as the ability of a social innovation or network to turn transformative potential into transformative impact or change. We further contextualize transformative capacity as a social phenomenon that is a result of structure working on agents and agents working on structures (Giddens 1979, 1984). Such capacity for change does not emerge from top-down (structural) nor bottom-up (agentic) causes, but rather is the result of both working in concert. The path to transformative capacity has implicit tensions. We observed critical tensions between two types of boundary work, which when managed dynamically are productive of both knowledge and authority, themselves operating in tension and contributing to transformative capacity.

In the sections that follow we provide an overview of the case study and situate it as a transformative learning network. We detail our theoretical lens which combines ideas about boundaries and boundary work (Abbott 1998, 1999; Gieryn 1983; Wenger-Trayner and Wenger-Trayner 2015) with the critical realist theory of morphogenesis (Buckley 1967; Archer 1995, 2003, 2010, 2013) stitching together a unique framing that enables us to identify the social interactions that support transformative capacity of the network and ultimately transformation of the broader social-educational system. We then describe our methods for data collection and the qualitative and process tracing analysis that enabled a phenomenological exploration of the case data. Through our analysis we explain how two types of boundary work, building and crossing boundaries, are interdependently operating in productive tension and create conditions for transformation of a complex system as demonstrated through progressive cycles which support network learning and development of 
authority. The case analysis describes the evidence that boundary navigation supports learning, and boundary building generates authority enhancing transformative capacity of the network to influence change in the broader system. Further analysis employs a morphogenic lens to explore phenomena of system elaboration and productive tension over time. We posit that engaging in both types of boundary work promotes transformative capacity of a learning network by expanding knowledge resources and the authority to influence both practice and policy. Our intent is to contribute to network scholarship by infusing primary social theory about structure and agency into our explanation of boundary dynamics. The framework itself is intended to explain the critical role of different types of boundary work in the progression of a learning network in a way that is useful to those designing, leading or studying networked approaches to transforming complex systems. This work has relevance to the many fields that are networking for change, including education, the environment, public health, and other sectors.

\section{Science Policy and the National Alliance for Broader Impacts}

Since 1997, the U.S. National Science Foundation (NSF) has explicitly required researchers to articulate and plan activities to realize the 'broader impacts' or societal benefits of research in their proposals. The criterion encompasses the potential to benefit society and contribute to the achievement of desired societal outcomes. The way that the NSF director frames the purpose of broader impacts is "to engage the public in order to help improve understanding of the value of basic research and why our projects are worthy of investment" (NSF 2014: 3). Broader impact activities are those that enhance public safety, national security, economic prosperity, science learning, broaden participation in the scientific enterprise, and engage the public in science learning.

The policy is supported in legislation, most recently the America COMPETES Act reauthorizations of 2010 and 2015, a report from the National Science Board in 2011, and the American Innovation and Competitiveness Act (passed in December, 2016), which has reaffirmed the importance of broader impacts of research. While the expectation to produce broader impacts is increasing (NABI 2018), universities have found themselves ill-equipped to meaningfully address these requirements. Reasons include a lack of training for researchers to effectively engage audiences in their research activities (Adetunji and Renoe 2017), unsupportive reward structures (Risien and Nilson 2018), and challenges in establishing necessary partnerships across disciplines and organizations. Many researchers still treat the requirement superficially and are unable to integrate such work into their professional practice (Malcolm 2018; Risien and Storksdieck 2018). The NSF has taken concrete steps to improve processes to better support broader impacts, but change has been slow. The agency relies on the research community to shift how they value, review, and practice broader impacts; conversely, the research community looks to the agency for direction (NABI 2018).

In 2013 about 80 university faculty, outreach professionals, and administrators came together in the first Broader Impacts Summit, which led to the formation of 
the National Alliance for Broader Impacts (NABI). Supported from 2014 to 2019 by an NSF research coordination network award, NABI aims to foster development of sustainable and scalable institutional capacity to support broader impacts. NABI seeks to build individual capacity and cultivate a set of shared practices through a supportive community in which members can innovate and learn to build capacity for broader impacts in their home institutions. They serve the function of connecting the research community practice and capabilities with the NSF requirements for broader impacts. In early 2019 the network had more than 700 members participating with various levels of engagement. Many members work to support researchers in developing their broader impacts proposals, programs and partnerships. Some members are themselves researchers who are deeply committed to broadening the impact of their work. Other members are university leaders and administrators seeking to develop institutional level broader impacts infrastructures.

Annual Summits are the network's main venue for fostering connections between members. Between Summits, members maintain learning and exchanges on the NABI listserv and through other individual and small group interactions including campus site visits. One network member describes why they engage with NABI, "there are two things: it's the very deep and meaningful tie to the agencies and structures for decision-making; and the very deep and meaningful tie to the communities that are doing this work, [NABI is] a kind of go-to for those" (interview, June 2017).

In September of 2018, the NSF awarded a $\$ 5.2$ million award to the NABI leadership to build a resource center to serve the needs of the NABI network. An order of magnitude more than the initial research coordination network grant that supported NABI, the Center for Advancing Research Impact in Society, or ARIS, is now the host of the NABI community which changed its name to ARIS in 2020.

Here we consider NABI as a case study to understand transformative learning networks, how they grow, and how two types of boundary work support a productive tension between knowledge building and development of authority in the system. Below our use of "network" refers to NABI, and "system" refers to academia, the complex social-educational system that NABI sought to change.

\section{Transformative Learning Networks}

Many public sector networks, such as NABI, are designed with a core structure to support connection across organizations through social interactions. Networks may emphasize collective impacts, generative social impacts, collaborative regional civic outcomes, governance, or other priorities (Considine 2013; Innes and Rongerude 2013; Kania and Kramer 2011; Olsson et al. 2014; Plastrik et al. 2014). Our case, like other transformative learning networks, is a multi-sited, multiscalar, voluntary collaborative that nurtures professional learning and expertise in fields such as environmental management, public health, and education (Dolle et al. 2013; Goldstein and Butler 2010). Such networks enhance transformative capacity by promoting a common professional identity among members, and by guiding them to a shared understanding of how they can bring about change (Goldstein et al. 2017a). 
These networks maintain a loose and light structure (Goldstein et al. 2017b) and amplify opportunities for transformation by integrating diverse site-based priorities and innovations with facilitated community-wide interactions and learning (Goldstein and Butler 2009, 2010; Goldstein et al. 2017b). Learning networks "are attempted when deeply rooted obstacles to institutional change have proven resistant to both top-down or bottom-up change strategies" (Goldstein et al. 2017a: 4).

Recent works examining learning network facilitation practices, organizational learning, and transformative capacities in four learning networks provides insights into the important role of boundary work (Goldstein et al. 2017a; 2017b). Key actors navigate boundaries by circulating ideas and practices between network sites. Regular whole-network gatherings enable social learning among members who have different ways of knowing, social roles, training, and experiences. Network leaders cultivate interactions that contribute to network-wide shared identity, language, and professional practices; in so doing, they achieve coherence without overt coordination. These networks can have an emergent impact on higher-scale properties like federal policy.

Networks aim for a transformative capacity that is more than the sum of individual network members' activities (Goldstein et al. 2017b). We hypothesize that such capacity emerges from weaving together multiple perspectives and experiences (through boundary navigation) into shared understanding and identity (through boundary building) without collapsing into a single point of view or set of practices. Network leaders serve to mediate the relationship between heterogeneous sites and the collective whole, supporting expression and adoption of new professional identities that can promote higher-order coherence while also enabling preservation of site autonomy.

Leaders cultivate transformative potential without prescribing specific professional practices or a rigid organizing structure. Rigidly prescribed lines of communication exacerbate conflict between local and network-wide identity and objectives. On the other hand, networks with more fluid boundary practices are more capable of facilitating information flow, forging social ties, engaging in collaborative learning, and promoting a shared professional identity (Goldstein et al. 2017b).

\section{Theoretical Framing}

The conceptual framework of productive tension presented here results from examining NABI through the theoretical lens of boundaries and boundary work and by using the critical realist theory of morphogenesis, which are summarized in this section.

\section{Boundaries and Boundary Work}

Boundary work occurs at the intersections of social worlds (Star and Griesemer 1989) and in the spaces between bounded communities (Wenger-Trayner, E. and Wenger-Trayner, B. 2015). Such work was originally described by Gieryn (1983; 
1999) in terms of demarcation between groups; the stronger and more impermeable the boundaries, the better one group could be distinguished from another. Boundarywork was articulated as "strategic practical action" (Gieryn 1983: 23) strengthening and maintaining boundaries that separate distinct groups. Abbott (1998) emphasized how strong professional boundaries support jurisdictional authority in professional settings. Others consider boundary work not in terms of demarcation, but more in terms of socially mediated learning and collaboration that occurs across boundaries. For example, Engeström (2009: 68, 77) describes such boundary crossing as "sociospatial interactions" and activity that occurs across boundaries as a "socio-spatial expansion." Wenger-Trayner and Wenger-Trayner (2015: 17) conceptualize boundaries as "learning assets" or places in a landscape of practice where the knowledge resources from a multiplicity of communities of practice converge "rich with new insights, radical innovation, and great progress."

Boundary structures exist with varying degrees of permeability, which can enable or constrain social interactions that contribute to transformation. When boundaries are too formal and impermeable they contribute to system rigidity and stagnation of practice innovation, which causes isolation and stifles innovation and learning (Abbott 1998; Gieryn 1995; Seo and Creed 2002). On the other hand, more permeable boundaries can challenge and break apart strong social norms (Abbott 1995; Lamont and Molnár 2002) ${ }^{1}$. Building strong boundaries develops expertise and authority of a group (Abbott 1995; Gieryn 1983). Navigating across boundaries cultivates broad knowledgeability and potential for cooperative collective pursuits accomplished at the intersections of social worlds (Star and Griesemer 1989).

Gieryn (1983) understands boundaries as fluid and dynamic, socially constructed, and continually reconstructed over time. Such fluidity aligns with the idea that boundaries can give rise to new social entities, such as networks, as actors cross boundaries to come together around points of difference (Abbott 1995). Transformative learning networks emerge in the space between established boundaries as actors identify points of difference with their dominant disciplinary or professional communities and find alignment with actors across boundaries in other communities. The multiplex nature of boundaries - spanning across organizations, sectors, disciplines, and professional positions (Weber and Khademian 2008) - is a defining characteristic of these systems in which learning networks disrupt the status quo by facilitating new processes and relationships. Boundaries between sites are not just geographic, they also demarcate differences in institutional focus, culture, size, power structures, values, and norms of practice.

We pursue an understanding of boundary work in the context of all the complexities of boundaries themselves described above. In our observations, boundaries were multiplex barriers of difference between individuals and/or groups and were primarily professional in nature having to do with position, organization, and practices.

\footnotetext{
1 Permeability is used here similarly to how Lamont and Molnár (2002: 168) describe symbolic boundaries as "conceptual distinctions" over which actors and groups struggle and converge; and aligned with how Abbott (1995) describes proto-boundaries as unstable and dynamic boundaries that can eventually give rise to new social entities.
} 
Here we use the term boundary work specifically to include two types of work operating in productive tension in complex social systems and applied to learning networks. Boundary navigation practices include members noticing common practices, challenges, or goals across boundaries and taking steps to connect across boundaries to learn. This work extends to actors applying and adapting newly gathered knowledge, and aligning new practices and perspectives with other communities in their landscape of practice. Having expanded their knowledgeability, members can express and share it with the network community (Wenger-Trayner, E. and WengerTrayner, B. 2015). Networks bring actors together, reducing barriers to learning thereby growing knowledge resources of the collective. Networks may also work to build capacity for the considerable skills this type of boundary work entails (Kubiak et al. 2015). Boundary building includes efforts by network leaders and members to collectively cultivate a shared identity, history, and language and demarcate themselves from others (Gieryn 1983) as practitioners in a domain (Wenger 1998). A critical outcome of boundary building is professionalization of the role of network members in an emerging field. Network authority and influence in the broader system develops as outsiders recognize the expertise of the network. Members can in turn leverage the network to gain recognition and authority supporting the practices they employ at their sites.

Our conceptualizations of boundaries, as structures in complex social systems, and boundary work, as actions of agents in these systems, are influenced by the richness of perspectives across fields. Above we draw from organizational studies, public administration and policy, and science studies with considerable influence from learning theory, including communities of practice in landscapes of practice, and cultural historical activity theory. Below we delve into morphogenesis, which has not, to the best of our knowledge, been applied to understanding the role of networks in transformation.

\section{Morphogenic Processes of Transformation}

We build on, and seek to make accessible, the critical realist theory of morphogenesis (Archer 2003, 2010, 2013), selected because of its deep, nuanced and clarifying approach to the fundamental tensions of structure and agency. Morphogenesis offers useful conceptualizations of how transformation happens coupled with methodological guidance for observing it. Embracing complexity, we take a view of transformation that is processual, rarely with an identifiable beginning or end. Where "the present is not merely the linear successor of the past but a novel outcome of it" and each moment "absorbs the preceding one, transforming it and with it the whole, constituting in each cycle of the process a novel and never-to-be-repeated occasion necessarily grounded in its past, but always projected towards a not-yet knowable future" (Chia 1999: 220). Transformation is not merely the result of structures or agents of managed change, but of synergistic effects of many small and unrecognized acts that together stimulate change (Chia 1999, 2014; Tsoukas and Chia 2002). Complex systems, such as the social-educational system represented by our case study, 


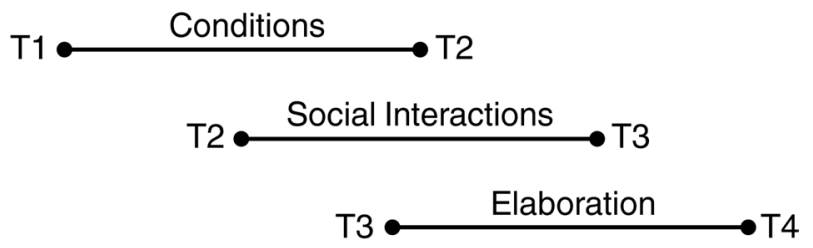

Fig. 1 Overlapping time segments of morphogenesis, adapted from Archer (1995)

undergoing transformation are in continuous states of emergence and are "above all the product of coupled, context dependent interactions" (Holland 2000: 121).

To account for the complexity one must consider both structure and agency as having causal powers in transformational processes. Therefore, structures can be understood as objectively determined and capable of supporting or impeding action (Merton 1968). Agency, on the other hand, is subjectively determined and understood as the capacity of individuals to make choices and to act on behalf of, or against, themselves or a collective (Bandura 1986). The specific relational arrangements in a system can enable or constrain change (Elder-Vass 2010; 2014). In this case, we argue that the relational arrangement in a transformative learning network enables both crossing and building boundaries in concert to support change.

Critical realism frames transformation as an intricate process that can be traced over time (Archer 2010, 2013) and assigns causal powers to both structures (e.g. network form) and agents (e.g. network members and leaders) in the system (ElderVass 2010). Buckley (1967) first described morphogenesis as processes in a complex system that elaborates system form or organizational state. In search of greater methodological clarity, Archer (2010, 2013) expanded on Buckley's ideas as she critiqued Giddens' accounts of change as mutually constituted by structures and agents (Bourdieu 1985; Giddens 1984). Archer claims the structurationists, particularly Giddens, confound the differences between structure and agency, making them analytically indistinguishable and robbing social scientists of opportunity to identify causal mechanisms in the system (Archer 2003; Parker 2000; Vandenberghe 2005). In Archer's dualist account of morphogenesis, transformation of structures and agents is interdependent, occurs through social interaction including the social construction of knowledge, and manifests in iterative system elaborations (Archer 1996, 2003, 2010, 2013). Morphogenesis is culturally and historically situated following a path in which system regression and transformation are both possible (López and Potter 2005) and a depth of context and intricate tracing of processes over time is required to explain structural elaboration (Archer 2010).

Structural elaboration is the result of morphogenic process and is not replacement of one state with a new state. Elaboration instead indicates a system with a "host of new social possibilities, some of which will come into play gradually" (Archer 2010: 241). Archer's original diagram of morphogenesis (1995: 157), adapted here as Figure 1, illustrates the non-linear and overlapping nature of system phenomena. It situates time (T) as critical in analysis of morphogenic cycles. Archer predicates her theory on structure (conditions T1-T2) logically predating action (social interactions T2-T3), action predating elaboration (T3-T4), and elaboration reinventing 


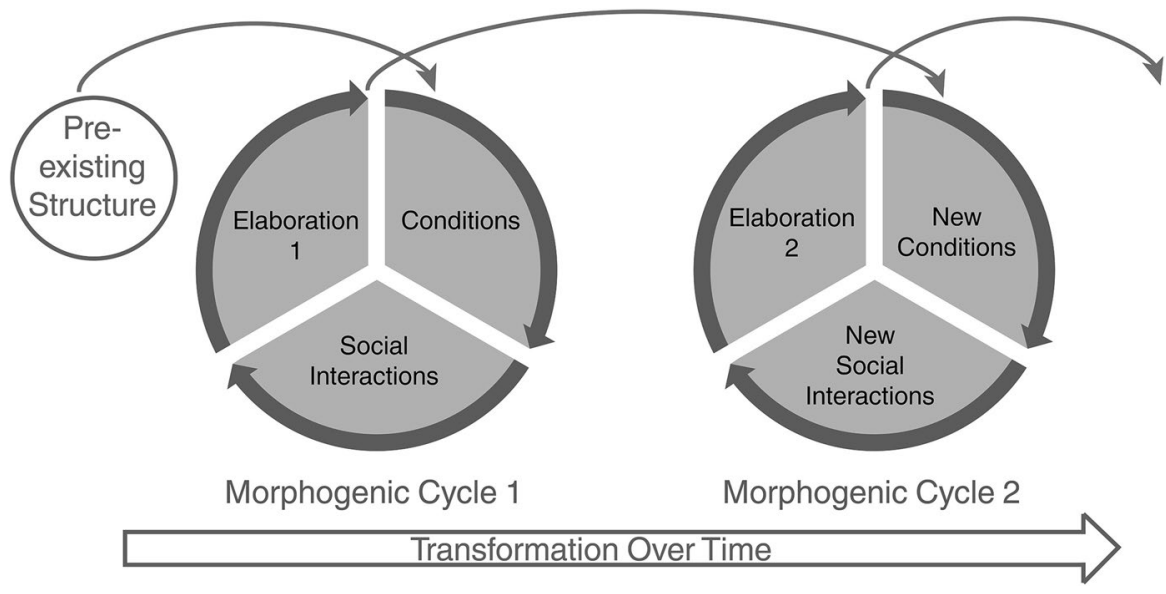

Fig. 2 Progressive morphogenic cycles

structure, thus beginning a new morphogenic cycle with new conditions (T4-T1). In each subsequent cycle "subjects are re-centered and structures are re-installed" (Parker 2000: 84). New conditions created by the previous elaboration are manifest in each cycle, and inherit the full context of the system history. In the progression, new structural conditions enable new types of social interactions. Agents have causal powers through social interactions and are themselves changed by system elaboration.

We developed Fig. 2 as an aggregate of key interpretations of morphogenesis. Parker (2000) visualized the connectedness between cycles and how each cycle propels subsequent cycles. Elder-Vass $(2010,2014)$ conceptualized the time segments in each morphogenic cycle as "moments." This synthesis serves as the foundation for our own processual analysis. We focus on the social-interactional moment that stimulates the process of morphogenesis (Elder-Vass 2010, 2014) through boundary work. In each cycle, the social-interactional moment (T2-T3) occurs in the context of the system conditions that exist in the structural moment (T1-T2) and results in the observable system elaboration (T3-T4).

\section{Methods}

We use qualitative analysis of a single in-depth case study (George and Bennett 2005; Goldstein and Butler 2009; 2010) to develop a framework around the productive tension of critical boundary work that propels the network. Our processual approach narrates and sequences emergent activities and properties to understand the patterns of the collective (Van de Ven and Poole 2005). The lead author participated, as a member, in network gatherings beginning in April 2014 and served on the network leadership team as an at large member (not supported by network associated grants) from January 2015 through the end of 2019. Embedded as a participatory researcher, and with explicit and continuous informed consent of the NABI 
leadership team, the lead author ethnographically captured the progression of NABI while maintaining the role of an active member of the leadership team. Our role was to observe and analyze system conditions and phenomena over time. Evaluation of network success was a separate process conducted by external evaluators who did not contribute to this study.

Data collection was multifaceted, which enabled the development of process theory (Van de Ven and Poole 2005). It included participant observation of monthly network leadership calls, biennial multi-day steering committee meetings $(n=7)$, advisory board meetings $(n=3)$, and annual full network gatherings $(n=4)$. Observations were also conducted during meetings with National Science Foundation (NSF) staff and private foundations interested in supporting and adding energy to the transformation NABI seeks. All observations were captured in detailed ethnographic style field notes and iteratively interpreted through research memos. Additional data came from semi-structured interviews $(n=18)$, which focused on understanding the everyday work and professional identities of network members. Participants of the 2017 annual network gathering $(n=95)$ responded to a survey including open ended questions about how members see the role of the network creating systemic change around broader impacts and their own roles in the network.

We applied emergent open coding procedures (Miles et al. 2014) to analyze and categorize all field notes, interview transcripts, and open-ended survey responses resulting in 460 substantive and unique excerpts coded as having to do with boundaries and boundary work as described above. No excerpts from the participating lead author were included in the dataset. These excerpts were subjected to a second round of open coding during which we parsed them into structural and agentic aspects while also identifying types of boundaries and types of boundary work. Excerpts were then sequenced and further evaluated through process tracing focusing on change over time. Process tracing involved inferences whereas acts of boundary work that occurred prior to intermediate network outcomes were considered as factors that contributed to those outcomes. The selection of intermediate outcomes were informed by network priorities and observations of the leadership team repeatedly discussing significant progress towards achievement of network goals. This type of process tracing aims to build plausible and generalizable middle-range theory that highlights possible causal mechanisms based on richness of evidence in a single case (Beach and Pedersen 2013). We use the above approach to build a conceptual framework that captures the productive tension between learning and authority and between boundary navigation and boundary building in a learning network.

\section{Study Limitations}

There is an inherent paradox in disentangling features of a network, an inherently complex social entity, to explain how they relate to one another. We recognize the risk of a reductionism that would discount the very complexity so central to our morphogenic lens, and we identified some unavoidable issues. For instance, while we maintained a coherent and progressive sense of time and process, we realize that the assignment of a specific time to elaboration from one morphogenic cycle to the 
next helps with descriptive clarity, but is ultimately subjective. Our understanding of the broader social-educational system we examined and the pre-existing conditions deeply influenced detections of shifts from one morphogenic cycle to the next (Archer 2003, 2010). One may reanalyze the system to examine phenomena other than the tensions and relationships between boundary work, authority and learning, and the results would likely identify different punctuating moments of elaboration. This is acceptable because we aimed to capture processes and interdependent actions and conditions as the system elaborated and transformed. The specific moment a system moves from one subjective state to the next is inconsequential to the phenomenon of productive tension. We acknowledge our lens of boundary work directly influenced our analytical choices and interpretation of viable causal inferences.

\section{Case Analysis}

Our analysis highlights several excerpts and examples from field data to illustrate how the network progressed during the period of observation. In this section, we first present observed boundary navigation practices as related to learning across boundaries, which served to expand the collective knowledge resources of the network. Next, we present observed boundary building actions as related to establishing the network's authority in the system. We consider these two, seemingly opposing, sets of activities as they propelled the network to grow and the system to elaborate in terms of morphogenic cycles. Then we describe the dialectic tension between the two types of boundary work. Together, these phenomena establish the case-basis for the conceptual framework.

Network boundaries were observed as socially constructed and manifest in a variety of structural configurations. The multiple boundaries relate to geographies, institution types, disciplines, professional roles, and power structures. We observed boundary structures as intricate, reflecting the complexity of the social-educational system in which they were observed. They served to demarcate one group of actors and set of practices from another, bolstering group claims of authority, enabling shared understanding and language, and lowering barriers to in-group collaboration.

\section{Boundary Navigation and Expansion of Knowledge}

University professionals working to support scientists in developing better broader impacts were responsible for the creation of NABI. One such professional describes initial efforts in simple terms, "I was struggling with this, and I was alone on my campus, I thought others must be struggling too, so I invited people to talk about it" (interview, Oct 2015). Bringing people with shared challenges together was a critical first step. This initial group established a mechanism for dispersed professionals to come together around similar experiences, bringing along their distinct contexts and points of view. Early members were able to discuss and build understanding about institutional conditions and social norms they perceived to impede progress on broader impacts. They reported grappling with similar issues such as disconnect 
between academic reward structures and quality broader impacts work. They shared their frustrations with the way many scientists placed low value on broader impacts work relative to disciplinary research. Broader impacts support was, at that time (2013), only recognized as a professional activity on a few campuses despite the fact that many had been performing the role. After the initial Summit, a small group submitted a proposal to NSF to form the network. NSF began modest support for what one high level NSF representative referred to as an "experiment [to] move the needle on broader impacts" (observation, April 2016). NABI leadership introduced a regular rhythm of facilitated networking opportunities for university-based broader impacts professionals through the annual Summits and a listserv.

During the Summits and on the listserv, NABI members engaged with peers from other institutions. They shared tools and ideas, discussed their experiences experimenting with new approaches, and showcased progress toward broader impacts infrastructure and support activities on their campuses. Sophistication of presented institutional models and guidelines for practice increased over time. Leadership in NABI provided ample open and unstructured time to promote deeper connection between members and encouraged them to share challenges as well as successes. Early in the network, the leadership often reminded members that everyone was learning together, since "nobody is an expert here" (observation, April 2015).

Members reported that engagement with NABI provided regular access to influencers at the national scale. These included representatives of university associations and NSF personnel who shared the network goal of advancing broader impacts practices. This influence deepened as veteran network participants began to recognize their own expertise. Over time other universities, NSF and other organizations, sought out network experts for their individual knowledge and ability to tap into the collective knowledge of the network.

A year and a half after NABI began, one network leader shared in a steering committee meeting that an early goal was to refine and then propagate a specific institutional model that was working well at one university. The leaders reported that expectations shifted over the first two years of the network as they embraced experimentation at each institution and encouraged members to evolve models that made sense for their own institutional structures and cultures. During early observations, members acknowledged that while they participate in NABI with the intention of learning collaboratively, their institutions were also in competition with one another to improve broader impacts to grow their own institutions research portfolios. Initially, in this context of competition, we observed members were reluctant to share tools and resources that they had created for their own campuses. Members soon opened up, crossing boundaries to share more resources with colleagues through the network and help each other through the listserv. Interviewed members also reported that they collaborated and shared resources in pairs between network gatherings.

Although the NABI leadership explicitly avoided prescribing specific institutional models for addressing broader impacts, best practices emerged. A group of members, working through the network, created a synthesis of such practices and published a guiding principles document (NABI 2016). This document served as a reflection of core practices exposed, tested, and in some cases innovated through interactions facilitated by the network. Members reported using the guiding 
principles document to anchor consultations with scientists developing broader impacts plans. It was also used to engage administrators who were in a position to support members' broader impacts roles. Some NSF programs also used the document to orient review panels to principles they may use in their review of broader impacts aspects of proposals.

As NABI members developed knowledge and experience, they began to request opportunities for more advanced learning at network gatherings. They also requested additional formalised knowledge products, like the guiding principles document, to support their site-based work. As seasoned members sought opportunities for more specialised learning, they also identified themselves in survey responses as "broader impacts innovators" central to the development of the profession. The broader impacts community had elaborated, progressing from a group of unconnected, sitebased non-experts to a network with a regular rhythm of opportunities for connection and learning. As the network developed collective knowledge about broader impact infrastructure and practices, new members continued to join and began their work from the learned position achieved by those already in the network. They experienced a lower barrier to entry and were more readily able to understand the challenges and promising practices around broader impacts.

Rapid growth in NABI membership indicated increased demand for broader impacts knowledge. Members also reported that scientist were seeking their services more frequently than they could accommodate. As NABI developed robust knowledge resources, more individuals and organizations not directly involved in the network sought out advice and products of the network. The broader impacts community progressed and conditions appeared to change as campus momentum and expectations around broader impacts accelerated. The demand for access to network knowledge extended beyond those who were themselves engaged in the network. Many peripheral actors were simply looking for access to information about developed techniques for application in their own work. The NABI leadership identified the next step in the evolution of the network with an ultimately successful long-term plan to maintain the learning network and additionally build a resource center to serve the expanding needs of the community.

Above we have traced boundary navigation activities, crossing many different types of boundaries to learn and build knowledge resources. Below we trace the boundary building activities in relation to developing authority of the network in the system over the same time period.

\section{Boundary Building and Expansion of Authority}

Network authority in the broader impacts domain grew as the network progressed. NABI leaders designed annual gatherings with express intention to facilitate deeper shared meaning, histories, language, and experiences among active members. These annual summits were critical in building boundaries that demarcate who is in the network and who is not. Participation distinguished members as change agents. Active members reported that NABI gatherings energized and emboldened them when they had previously felt alone or powerless in their efforts to promote broader 
impacts on their campus. One member expressed a sentiment, shared by many others throughout the life of NABI, at the end of a gathering, "I've finally found my tribe!" (observation, April 2014). Another referred to NABI shortly after attending a summit as "my affinity group, I've found my affinity group!" (interview, May 2015).

NABI leadership maintained an ethos of openness and sharing among members and used the rhetoric of family during the annual events. The leadership intentionally boosted members' sense of shared identity as broader impacts professionals, "we are all in this together, we are all figuring this out together" (observation, April 2015). Network leaders told the history of NABI at the beginning of each gathering bringing new members up to date and explicitly including them in the shared story of the network from that point forward. At the end of each gathering, leaders revisited the history and added a new chapter through group reflection on the learning and personal connections achieved at the Summit. During town hall style sessions at the closing of each summit, NABI leaders issued calls to all members to reach out and contact other members with any need. They empowered members as broader impacts professionals with a right to claim expertise in the professional domain. For example, one leader acknowledged the growing expertise in the room by asking for a raise of hands on how many grant proposals members work on each year, "more than 20 , more than $10 \ldots$ ?" The leader then asked the membership to remember that the scientists they support may only work on a few proposals per year as they claimed, "we are the ones with expertise on this" (observation, April 2015). In that same session, a member of the network leadership pointed out the group's ability to take collective action, saying "I'm not saying we should all become lobbyists, but...that's the power of us all in one network distributed all over the place... we need to engage our politicians... show them the good things that are happening in their districts" (observation, April 2015). Finally, attention to shared language had also been an important and ongoing discussion in the network - as one member put to the group, "What do we mean when we say "broader impacts", and, "the language we use is important." Another member responded that, "it's still not clear what NSF wants, what they mean by innovative approaches [to broader impacts]." Network leaders responded, and participating members agreed that it is "up to us, if NSF doesn't know [what they mean by innovative broader impacts], then we have an opportunity here" (observation, April 2015), indicating that the network had the authority to define the terms of broader impacts innovation.

Another regular activity that expanded network authority was cross-site visits, during which small groups of NABI members and leaders provided broader impacts trainings and met with university administrators on other campuses. Network leaders used these opportunities to inform administrators of the national momentum and evolving NSF policies on broader impacts. Some of these visits influenced institutions to increase support or allocate new resources to broader impacts support. For example, one campus established a new broader impacts initiative and hired a local active NABI member to direct it. Members who hosted NABI visitors on their campuses reported that visits stirred university administrators' sense of competition with peer institutions, which encouraged them to invest resources or better value the work of broader impacts professionals. Members also reported that such visits to their campuses provided them with enhanced access to campus administrators. 
In 2017, there was a marked increase in program administrators and other people in positions of power engaged with NABI members to improve broader impacts practice on their campuses. For instance, an NSF Assistant Director, having recently returned to a university upper administration position, signed on to serve on the NABI advisory board. The NSF Director of the Office Integrative Affairs travelled from D.C. to the west coast to participate in the annual network gathering during which she delivered a keynote speech. NABI was approached by, and garnered support from, a private foundation interested in advancing broader impacts practice. The foundation helped to convene university administrators, representatives from university associations and foundations, exemplar scientists, and key NABI members and NSF staff in a two-day workshop to assess national progress on improving broader impacts (NABI 2017).

Over the course of five years the network progressed from a handful of individuals coming together to tackle shared challenges to a several hundred member national community recognized for its expertise and knowledge. In the next subsection we identify system elaboration and connect critical boundary work - navigating to enable learning and building to develop authority - to morphogenic cycles.

\section{System Elaboration}

In 2017, the network was continuing to grow, but at a slower pace. New members reported significant individual gains in broader impacts knowledge and authority. However, the knowledge and experiences of these new members already existed in the network; they did not substantially contribute to network knowledgeability. Network acquisition of knowledge resources and the developmental pace of the network, in terms of expansion of authority in the system, was levelling off. At the same time many seasoned members reported that what they had learned in the network contributed to professional advancement. For example, some members established durable, and in some cases well-resourced, broader impacts infrastructure at their sites. We interpret this as an indication of system elaboration from one morphogenic cycle and set of conditions to a qualitatively different set of conditions in a subsequent cycle (see Cycle 2, Table 1).

The NABI leadership took notice that many members needed a different, more advanced, sort of engagement and took measures to adapt gatherings and network offerings to meet the needs of those members. The 2018 Summit included a research track to emphasize scholarship of broader impacts reflecting the focus of veteran members on developing scholarship in the domain in which they have already worked to advance practice. NABI also engaged with organizations working to establish broader impacts journals to ensure that the journals would match the needs of NABI members and their collaborators. A subset of the NABI leadership proposed a resource center to the NSF with an aim to develop extensive resources that support broad-scale improved broader impacts practice. The group began working to provide more direct resources for broader impacts to scientists and the professionals that support them. In 2018 the NSF supported the proposed resource center. The emergence of the center established a new set of conditions where broader impacts 
Table 1 System conditions observed (T1-T2) in each of three morphogenic cycles.

\begin{tabular}{|c|c|c|c|}
\hline & Cycle 1 & Cycle 2 & Cycle 3 \\
\hline \multirow{3}{*}{ 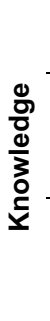 } & $\begin{array}{l}\text { no mechanism for social } \\
\text { interaction }\end{array}$ & $\begin{array}{l}\text { regular network facilitated } \\
\text { social interactions }\end{array}$ & $\begin{array}{l}\text { sustained social and } \\
\text { organizational channels }\end{array}$ \\
\hline & $\begin{array}{l}\text { knowledge resources are } \\
\text { limited and dispersed }\end{array}$ & $\begin{array}{l}\text { expanded embodied } \\
\text { knowledge and resources }\end{array}$ & $\begin{array}{l}\text { knowledge base well } \\
\text { established, scholarship } \\
\text { emerges }\end{array}$ \\
\hline & $\begin{array}{l}\text { practices are unrefined or } \\
\text { occur in isolation }\end{array}$ & $\begin{array}{l}\text { best practices exposed, } \\
\text { applied and openly } \\
\text { available }\end{array}$ & $\begin{array}{l}\text { best practices are } \\
\text { normalized and expanded }\end{array}$ \\
\hline \multirow{3}{*}{ 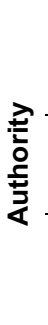 } & $\begin{array}{l}\text { isolated individuals } \\
\text { working w/out authority }\end{array}$ & $\begin{array}{l}\text { increased individual } \\
\text { efficacy, bolstered by } \\
\text { network }\end{array}$ & $\begin{array}{l}\text { individuals identify as } \\
\text { experts, profession is } \\
\text { normalized }\end{array}$ \\
\hline & $\begin{array}{l}\text { institutions are unaware } \\
\text { of challenges }\end{array}$ & $\begin{array}{l}\text { institutions invest } \\
\text { resources to support } \\
\text { practice }\end{array}$ & $\begin{array}{l}\text { institutional infrastructure } \\
\text { is normalized }\end{array}$ \\
\hline & $\begin{array}{l}\text { network emerges to } \\
\text { define problems and } \\
\text { domain }\end{array}$ & $\begin{array}{l}\text { network influences } \\
\text { allocation of resources }\end{array}$ & $\begin{array}{l}\text { network influence } \\
\text { expands, becomes } \\
\text { professional association }\end{array}$ \\
\hline
\end{tabular}

support practice began to be recognized by those outside the network as a profession and institutional broader impacts infrastructure was becoming normalized. The center also enabled new types of social-interactions such as providing expert-level training, engaging members to develop additional center-branded resources, maintaining a more substantial web presence, and actively promoting scholarship around broader impacts (see Cycle 3, Table 1).

Our analysis concentrates on morphogenesis as a process whereby a social-educational system progresses the standing of and support for broader impacts from cycle to cycle through network-mediated boundary work. Table 1 describes system conditions prior of the creation of the network as cycle one and the conditions as of early 2018 as evidence of elaboration into cycle two. The conditions of cycle three more recently emerged with the creation of the resource center and the new social interactions of cycle three underway. This includes recent emphasis in the network on broader impacts scholarship, synthesis of existing information and expertise into tools and training resources. Under the new resource center, NABI is transitioning to operate as more of a professional organization. This transition is a departure from the loose and light structure of a learning network with more clearly delineated boundaries, less emphasis on collaborative learning, and a more mature sense of authority. This description of the network over time demonstrates how networkmediated boundary work is a social-interactional driver of system elaboration establishing new conditions in terms of knowledge and authority in subsequent cycles.

Boundary navigation began before and contributed to the emergence of the network itself; this work resulted in the construction and flow of knowledge and expanded knowledge resources as the network grew. In relation to morphogenesis, agents engaged in boundary navigation shifted broader impacts practice by 
enriching the system with network-mediated social interactions and opportunities for learning. As cycle one began, the system was void of regular mechanisms for connection and social interaction between sites and between practitioners. Knowledge resources were limited and dispersed among disconnected practitioners and sites. Cycle one practices generally occurred in isolation and under conditions that did not support sharing or collective refinement. In cycle two, the network facilitated a regular rhythm of opportunity for social interactions around broader impacts. The network, through boundary navigation, cultivated individual and collective learning. As the system progressed to cycle two, best practices emerged based on repeated member experimentation across sites and communication through the network about successes and challenges. Network facilitation and structure enabled and prioritized open sharing of tools and principles to guide practice.

Boundary building increased the authority and influence of the network over time. This occurred across scales, from site-based influence leveraged by members to national influence leveraged by network leaders ${ }^{2}$. Network agents engaged in acts of boundary building, shifting conditions of authority and influence from one cycle to the next. In cycle one, the broader impacts domain was not established, there was no legitimate claim of authority, and only a few campuses had invested resources to support broader impacts infrastructure. In cycle two, boundary building effects were most apparent for individuals who experienced increased efficacy in their own work which they attributed to network interactions; these individuals were able to leverage the influence of the network to garner local resources and support. In cycle three, more collective effects became apparent as the field professionalized and the new conditions supported development of new and improved broader impacts norms of practice. Scientists outside the network had increased access to broader impacts support and increased understanding of how to include broader impacts practices and partnerships in their research.

\section{Productive Tension in the Network}

The two types of boundary work, dynamic within the network and the broader system, pulled the network in two directions concurrently. For example, early leadership meetings included extensive deliberation about appropriate network boundaries. They struggled to define who should and should not be in the network and debated about the trade-offs and advantages of establishing such boundaries. Ultimately, they decided to maintain fluid boundaries while acknowledging that the choice made developing shared language and identity more difficult. They spent significant effort on supporting shared identities, language, and histories among network members both explicitly demarcating the domain of broader impacts while intentionally maintaining open participation. These examples capture the dialectic tension between the two types of boundary work and the ultimate progressive synthesis of a network

\footnotetext{
${ }^{2}$ Risien (2019) offers an analysis of the multi-sited and multiscalar characteristics of NABI and the distinct roles of members and leaders.
} 
that dynamically manages both. On one side, through navigation, they maintained an open, fluid, heterogeneous, experimentally driven, context-valuing network. On the other side, through boundary building, they defined membership, practices, language, and norms in ways that enabled claims of authority in the system.

It may seem that knowledge construction stemmed from boundary navigation and expansion of authority that resulted from boundary building are separate cause and effect stories. However, while we disaggregate them to provide clarity in our explanation, they are fully intertwined. For example, cross-site visits served to build boundaries, by expressing network expertise across sites and to campus decision makers. Those visits also helped local members navigate boundaries across a power differential, since the presence of visitors prominent in the network often provided members with additional access to decision makers at their own institution. The knowledge resources of the network influenced claims of authority, and vice versa. When knowledge resources were limited, the perceived value of the network to outsiders was also limited, stifling any claim to authority. Conversely, when outsiders recognized network authority, membership grew thereby increasing the knowledge assets of the network.

This case analysis was built on empirical data collected over nearly six years. It provides evidence about the tensions between learning and authority and the need to dynamically engage in boundary navigation and building to cultivate transformative capacity dependent on knowledge and authority. We presented the case as three morphogenic cycles, where system conditions (T1-T2), initially described in the introduction, are connected to each cycle iteration in Table 1. Social interactions (T2-T3) are described in terms of boundary work, which is critical to the progressive phenomena of learning and authority of the network. Elaborations (T3-T4) are noted as times when qualitatively significant change was observed and renewed conditions forthcoming: the emergence of the network (Cycle 1); the slowing of the developmental pace of the network (Cycle 2); and the creation of a well-funded resource center (Cycle 3). Our analysis and use of the morphogenic lens embraces the complexity and dynamism of the social-educational system broadly and NABI as a learning network more specifically. The resulting conceptual framework in the next section seeks to make the complexities more accessible by illustrating network progression as simplified to capture the critical tensions, the dialectic, and long-term nature of transformation.

\section{Results and Discussion}

The single case analysis provided the primary empirical basis for the conceptual framework below. We intend to enable network designers, leaders, and scholars to access and apply the theories that shaped our analytical lens in development, management, and scholarly inquiry of other transformative learning networks. The framework explains the critical role of boundary work (key social interactions) and the growth of knowledge and authority as assets of a network (key indicators of transformative capacity) as a learning network progresses over time. We 


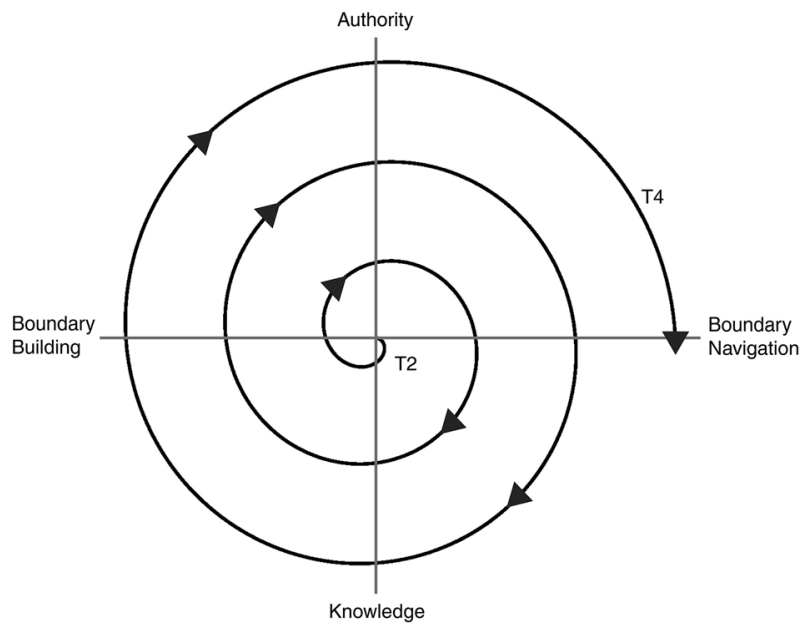

Fig. 3 Conceptual framework of productive tension through network progression

conceptualize the tensions and progression on a long time scale where the complexity and non-linear progression is smoothed to illustrate the tensions at play and an overall system progression without the noise of complexity.

\section{A Conceptual Framework: Productive Tension of Critical Boundary Work}

The spiral (Fig. 3) illustrates network pre-emergence and progression driven by boundary work that occurs in the social-interactional moments of morphogenic cycles (see Figs. 1 and 2). The first social-interactional moment begins prior to network emergence (T2) and tracks progression to where a mature network has transformative capacity and evidence of elaboration is observed (T4). The two types of boundary work operate in productive tension, interdependently and synergistically contributing to this progression. Tracing through time, initial boundary navigation increases opportunity for network actors to organize into a collective and build knowledge through both exposure and co-construction across many types of boundaries. Second, boundary building progressively supports authority of the network and its members in the domain. As the network develops and members conduct both types of boundary work, authority and knowledge expand.

Figure 3 illustrates the two tensions along axes. The tensions exist in 1) doing work ( $\mathrm{x}$-axis) between boundary building and boundary navigation, and 2) producing resources (y-axis) between knowledge and authority. The time stamps in this processual diagram intentionally correspond with Archer's (1995: 157) initial diagram representing the passage of time $(\mathrm{T})$ in morphogenesis (see Fig. 1). Archer disentangles: the structural moment where system conditions are identified (T1 to T2); the social-interactional moment when social interactions and practices work to shift conditions (T2 to T3); and elaboration when the system can be observed as qualitatively distinct from the previous cycle (T3-T4). Here we capture the emergence of a learning network as logically stemming from 
system conditions and the beginning of a new set of social interactions (T2). Revolutions represent progressing morphogenic cycles inclusive of network-mediated phenomena - boundary navigation contributing to growing knowledge and boundary building contributing to cultivating authority - where each cycle repeats each of the three moments of morphogenesis, culminating in the transition between elaboration and a new set of conditions (T4-T1).

New practices innovated within and shared through the network slowly replace old norms of practice, contributing to system elaboration. The next morphogenic cycle inherits the elaborated system conditions, including new structures, cultural conditions, and updated norms of practice. As this implies, the initiation of the network occurs in the context of pre-existing structures and conditions that support certain norms of practice. During this shift from norm-supporting conditions to disruption, there may already be instances of people in the system regularly engaging in non-normative practice. Conditions however, serve the normative practice of the given morphogenic cycle and challenge development and propagation of new practices that may come to dominate in subsequent cycles, when conditions are more favourable. The network develops transformative capacity, captured in this model as expansion of knowledge and authority resulting from a dynamic use of boundary work, which disrupts the status quo. The structural moment of each cycle brings changes to system conditions that enable new norms of practice in the broader system. When previously non-normative practices become the new norm and are supported by conditions, the system has elaborated and moves into a new cycle. Conditions and actions are re-centered (Parker 2000); the system is transforming.

This framework builds on critical realism's contemporary theory of morphogenesis and insights from social learning theory and processual philosophy. It explains how two types of boundary work exist in a productive tension and how that very tension can contribute to transformative capacity over time. Our embedded approach enabled us to follow the network as it elaborated, through morphogenic cycles, into a hub of knowledge and source of authority in the system. In this case, we examine transformative capacity cultivated through a learning network; we posit that such capacity manifests as a combination of a network's robust knowledge resources and authority in the broader system. We observed these resources to expand overtime, be in tension with each other, and result from network leaders dynamically balancing two types of boundary work.

\section{Conclusion}

Understanding the dynamic, complex, and non-linear subtleties of transformation helps researchers and practitioners, ourselves included, to engage in robust conversations with partners about the nature of transformation a the role of social innovations in transforming complex systems. We can better understand the path to transformative capacity when we can disentangle the causal powers of structures and agents and resist the urge to assign causal power to one over the other. The way a system is structured and actions people take are influenced by history, context, conditions, 
relationships, and interactions. A morphogenic lens can help partners understand that neither top-down (structural) nor bottom-up (agentic) approaches will alone be sufficient to stimulate transformation (Butler and Goldstein 2010; Goldstein et al. 2017b). Transformation is slow, difficult to measure, and the result of many small acts and disruptions in a complex system (Tsoukas and Chia 2002). Simply changing practice or conditions will not lead to transformation. Understanding how social interactions and structural conditions are intertwined may support change makers in establishing thoughtful directed action toward building transformative capacity and systems change.

This study answers calls to examine whole networks in their full and complex contexts (Keast and Mandell 2013; Knight and Pye 2005; Provan et al. 2007; Raab and Kenis 2009), and expand focus beyond network structure and leadership (Kezar and Gehrke, 2015). Our productive tension of critical boundary work framework provides a theoretical bridge between network-mediated transformation literature and complex social systems theory. We highlight the tensions and interdependence of structure and agency and the social-interactional activity that enables a network to build transformative capacity; suggesting learning networks can have a robust role in fostering system transformation. Our morphogenic framework can be used to further develop network studies that focus on multiscalar learning and innovation (Goldstein et al. 2017b; Olsson et al. 2014; Rosen and Olsson 2013; Strasser et al. 2019) and work that underscores network mechanisms of empowerment (Avelino et al. 2020; Loorbach et al. 2020). Our framework describes how transformative capacities are drawn together and productively held in a network, iteratively and recursively (Scearce 2011), expanding knowledge and authority resources to foster transformation over time.

Positioning this work in practice, we conclude that leaders and designers may be able to enhance practice when attuned to the dynamic tensions of boundary work. Thoughtful engagement with the dialectic between knowledge and authority is important for developing transformative capacity. With this in mind, network designers and practitioners can intentionally balance enhanced learning opportunities offered by fluid navigable boundaries alongside increased influence of a network with clearly defined and maintained boundaries. Achievement of transformative capacity requires attention to both boundary navigation and boundary building practices, shifting dynamically between two types of effort while avoiding overemphasis on one or the other. In our observations, network leadership did not always agree on how to manage boundaries in an inherently unbounded community. Each leader brought their own notions about how best to achieve change. While some privileged the multiple perspectives and welcoming nature of open network boundaries, others privileged the strong organizational identity of a more homogeneous and clearly defined membership. However, expansion of knowledge and authority were not in conflict, but mutually constituted. The boundary work tensions challenged network leaders to accept change as a long-term process (Stachowiak and Gase 2018) and to accept both the ambiguity and the unsung nature of their central roles (Holley 2012). In so doing they enabled many small relational acts that supported system elaboration. Network leaders who can treat boundaries dynamically, flexibly shifting 


\section{emphasis between strength and fluidity, can leverage learning networks to enable system transformation.}

Acknowledgments The authors thank the leadership and members of the National Alliance for Broader Impacts and the Advancing Research Impacts in Society Center along with National Science Foundation employees for generously sharing their time and work. Also thanks to our colleagues at the University of Colorado Boulder (www.brugo.org) for expanding our thinking and sharing insights from their own case work. Thank you to the STEM Research Center at Oregon State University for providing the space and time to conduct this work. Additional thanks to Ann Sitomer and two anonymous reviewers for their thoughtful pre-submission reviews. Field work for this project was supported in part by the National Science Foundation (1408736 and 1524832) and the Kavli Foundation.

Authors' contributions The lead author (Julie Risien) conceptualized, designed and conducted the study. Julie Risien drafted the manuscript. The second author (Bruce Evan Goldstein) reviewed the manuscript and advised on interpretative analysis of the data. Both authors read and approved the final manuscript.

Funding Field work for this project was supported in part by the National Science Foundation $(M C B$ \#1408736) and the Kavli Foundation.

\section{Declarations}

Competing interests Not Applicable.

Consent to participate Participants in interviews and closed door observations underwent a continuous informed consent process through which they received and IRB approved informed consent explanation of study document and verbally consented to confidential participation. Participants in public meetings were not required by the IRB to provide consent as they were being observed as part of their normal professional duties (study \#7286)

Consent for publication Under the IRB publications may not include any information that would allow readers to identify participants. This manuscript therefore does not include names, organizational affiliations or other identifiable information about participants including those observed with and without informed consent.

Ethical approval This study was approved and conducted under compliance with the Oregon State University Institutional Review Board study \#7286.

Open Access This article is licensed under a Creative Commons Attribution 4.0 International License, which permits use, sharing, adaptation, distribution and reproduction in any medium or format, as long as you give appropriate credit to the original author(s) and the source, provide a link to the Creative Commons licence, and indicate if changes were made. The images or other third party material in this article are included in the article's Creative Commons licence, unless indicated otherwise in a credit line to the material. If material is not included in the article's Creative Commons licence and your intended use is not permitted by statutory regulation or exceeds the permitted use, you will need to obtain permission directly from the copyright holder. To view a copy of this licence, visit http://creativecommons.org/licen ses/by/4.0/.

\section{References}

Abbott, Andrew. 1995. Things of boundaries. Social Research 62(4): 857-882.

Abbott, Andrew. 1998. The system of professions. Chicago, IL: University of Chicago Press. 
Adetunji, Oludurotimi, and Susan D. Renoe. 2017. Assessing Broader Impacts. MRS Advances 2(31-32): 1681-1686.

Archer, Margaret S. 1995. Realist Social Theory: The Morphogenetic Approach. Cambridge, U.K.: Cambridge University Press.

Archer, Margaret S. 1996. Social integration and system integration: developing the distinction. Sociology 30(4): 679-699.

Archer, Margaret S. 2003. Structure, Agency and the Internal Conversation. Cambridge, U.K.: Cambridge University Press.

Archer, Margaret S. 2010. Morphogenesis versus structuration: on combining structure and action. The British Journal of Sociology 61(1): 225-252.

Archer, Margaret S. 2013. Social origins of educational systems. London: Routledge.

Avelino, Flor, Adina Dumitru, Carla Cipolla, Iris Kunze, and Julia Wittmayer. 2020. Translocal empowerment in transformative social innovation networks. European Planning Studies 28(5): 955-977.

Bandura, Albert. 1986. Social foundations of thought and action: A social cognitive theory. Englewood Cliffs, NJ: Prentice-Hall.

Beach, Andrea L., Mary Dean Sorcinelli, Ann E. Austin, and Jaclyn K. Rivard. 2016. Faculty development in the age of evidence: Current practices, future imperatives. Sterling, VA: Stylus Publishing LLC.

Beach, Derek, and Rasmus Brun Pedersen. 2013. Process-tracing Methods: Foundations and guidelines. Ann Arbor, MI: University of Michigan Press.

Bourdieu, Pierre. 1985. The genesis of the concept of habitus and field. Sociocriticism 2(2): 11-24.

Buckley, Walter Frederick. 1967. Sociology and Modern Systems Theory. Englewood Cliffs, NJ: Prentice-Hall.

Butler, William H., and Bruce Evan Goldstein. 2010. The US Fire Learning Network: springing a rigidity trap through multi-scalar collaborative networks. Ecology and Society 15(3): 21.

Chia, Robert. 1999. A rhizomic model of organizational change and transformation: Perspective from a metaphysic of change. Journal of Management Studies 10: 209-227.

Chia, Robert. 2014. Reflections: in praise of silent transformation - allowing change through 'letting it happen.' Journal of Change Management 14(1): 8-27.

Considine, Mark. 2013. Governance networks and the questions of transformation. Public Administration 91(2): 438-447.

Dolle, Jonathan R., Louis M. Gomez, Jennifer Lin Russell, and Anthony S. Bryk. 2013. More than a network: building professional communities for educational improvement. Teachers College Record 115(14): 443-463.

Elder-Vass, Dave. 2010. The causal power of social structures: emergence, structure and agency. Cambridge, U.K.: Cambridge University Press.

Elder-Vass, Dave. 2014. Social entities and the basis of their powers. In Rethinking the Individualism-Holism Debate, eds. J. Zahle and F. Colin, 39-53. Gewerbestrasse, Switzerland: Springer International.

Engeström, Yrjö. 2009. Expansive learning toward an activity-theoretical reconceptualization. In Contemporary theories of learning, ed. K. Illeris, 53-72. New York, NY: Routledge.

George, Alexander L., and Andrew Bennett. 2005. Case studies and theory development in the social sciences. Cambridge, MA: MIT Press.

Giddens, Anthony. 1979. Central problems in social theory: Action, structure, and contradiction in social analysis. Berkeley, CA: University of California Press.

Giddens, Anthony. 1984. The constitution of society: Outline of the theory of structuration. Cambridge: Polity Press.

Gieryn, Thomas F. 1983. Boundary work and the demarcation of science from nonscience: strains and interests in professional ideologies of scientists. American Sociological Review 48: 781-795.

Gieryn, Thomas F. 1995. Boundaries of science. In Handbook of science and technology studies, revised, eds. S. Jasanoff, G. Markle, and J.C. Petersen, 393-443. Thousand Oaks, CA: SAGE Publication.

Gieryn, Thomas F. 1999. Cultural boundaries of science: credibility on the line. Chicago, IL: University of Chicago Press.

Goldstein, Bruce Evan, and William H. Butler. 2009. The network imaginary: coherence and creativity within a multiscalar collaborative effort to reform U.S. fire management. Journal of Environmental Planning and Management 52(8): 1013-1033. 
Goldstein, Bruce Evan, and William H. Butler. 2010. The U.S. Fire Learning Network: providing a narrative framework for restoring ecosystems, professions, and institutions. Society and Natural Resources 23(10): 935-951.

Goldstein, Bruce Evan, Clair S. Chase, Lee Frankel-Goldwater, Jeremiah Osborne-Gowey, Julie Risien, and Sarah Schweizer. 2017a. Transformative Learning Networks: Guidelines and Insights for Netweavers. https://serc.carleton.edu/StemEdCenters/178058.html.

Goldstein, Bruce Evan, Clair S. Chase, Lee Frankel-Goldwater, Jeremiah Osborne-Gowey, Julie Risien, and Sarah Schweizer. 2017b. Transforming with a soft touch: comparing four learning networks. Systems Research and Behavioral Science 34(5): 537-543.

Haxeltine, Alexander, Bonno Pel, Julia Wittmayer, Adina Dumitru, Rene Kemp, and Flor Avelino. 2017. Building a middle-range theory of Transformative Social Innovation; theoretical pitfalls and methodological responses. European Public \& Social Innovation Review 2(1): 59-77.

Hill, Lucas B., Julia N. Savoy, Ann E. Austin, and Bipana Bantawa. 2019. The impact of multi-institutional STEM reform networks on member institutions: A case study of CIRTL. Innovative Higher Education 44(3): 187-202.

Holland, John Henry. 2000. Emergence: from chaos to order. Oxford: Oxford University Press.

Holley, June. 2012. Network weaver handbook. Athens, OH: Network Weaver Publishing.

Innes, Judith E., and Jane Rongerude. 2013. Civic networks for sustainable regions - Innovative practices and emergent theory. Planning Theory \& Practice 14(1): 75-100.

Kania, John, and Mark Kramer. 2011 Collective impact. Stanford Social Innovation Review (winter edition).

Keast, Robyn, and Myrna P. Mandell. 2013. Network performance: A complex interplay of form and action. International Review of Public Administration 18(2): 27-45.

Kezar, Adrianna. 2014. Higher education change and social networks: A Review of Research. The Journal of Higher Education 85(1): 91-125.

Kezar, Adrianna, and Sean Gehrke. 2015. Communities of transformation and their work scaling STEM reform. Pullias Center for Higher Education and Rossier School of Education, University of Southern California. https://pullias.usc.edu/wp-content/uploads/2016/01/communities-oftrans.pdf.

Knight, Louise, and Annie Pye. 2005. Network learning: An empirically derived model of learning by groups of organizations. Human Relations 58(3): 369-392.

Kubiak, Chris, Mark Fenton-O’Creevy, Karen Appleby, Maxine Kempster, Michael Reed, Carla Solvason, and Mary Thorpe. 2015. Brokering boundary encounters. In Learning in Landscapes of Practice: Boundaries, Identity, and Knowledgeability in Practice-based Learning, eds. E. Wenger-Trayner, M. Fenton O'Creevey, S. Hutchinson, C. Kubiak, B. Wenger-Trayner, 13-29. New York, NY: Routledge.

Lamont, Michele and Virag Molnár. 2002. The study of boundaries in the social sciences. Annual Review of Sociology: 167-195.

Lave, Jean, and Etienne Wenger. 1991. Situated Learning: Legitimate peripheral participation. Cambridge: Cambridge University Press.

López, José, and Garry Potter. 2005. After postmodernism: An introduction to critical realism. London: Athlone Press.

Loorbach, Derek, Julia Wittmayer, Flor Avelino, Timo von Wirth, and Niki Frantzeskaki. 2020. Transformative innovation and translocal diffusion. Environmental Innovation and Societal Transitions 35: 251-261.

Merton, R.K. 1968. Social Theory and Social Structure. New York, NY: Free Press.

Miles, Matthew B., A.M. Huberman, and Jonny Saldaña. 2014. Qualitative data analysis: a method sourcebook. Thousand Oaks, CA: Sage Publications.

National Alliance for Broader Impacts. January 2018. The Current State of Broader Impacts: Advancing science and benefiting society. https://www.broaderimpacts.net.

National Alliance for Broader Impacts. 2016. Broader Impacts Guiding Principles. https://www.broad erimpacts.net.

National Science Board. 2011. National Science Foundation's Merit Review Criteria: Review and Revisions. http://www.nsf.gov/nsb/publications/2011/meritreviewcriteria.pdf

National Science Foundation. 2014. Perspectives on Broader Impacts. Washington, D.C.: NSF. http:// www.nsf.gov/od/iia/publications/Broader_Impacts.pdf.

Olsson, Per, Victor Galaz, and Wiebren J. Boonstra. 2014. Sustainability transformations: a resilience perspective. Ecology and Society 19(4). 
Parker, John. 2000. Structuration. Buckingham: Open University Press.

Plastrik, Peter, Madeleine Taylor, and John Cleveland. 2014. Connecting to change the world: Harnessing the power of networks for social impact. Washington, D.C.: Island Press.

Provan, Keith G., Amy Fish, and Jörg Sydow. 2007. Inter-organizational Networks at the Network Level: A Review of the Empirical Literature on Whole Networks. Journal of Management 33(3): 479-516.

Raab, Jörg., and Patrick N. Kenis. 2009. Heading toward a society of networks: Empirical developments and theoretical challenges. Journal of Management Inquiry 18(3): 198-210.

Rosen, Franciska, and Per Olsson. 2013. Institutional entrepreneurs, global networks, and the emergence of international institutions for ecosystem-based management: the Coral Triangle Initiative. Marine Policy 38: 195-204.

Risien, Julie. 2019. Curators and sojourners in learning networks: Practices for transformation. Evaluation and Program Planning 73: 71-79.

Risien, Julie, and Roberta Nilson. 2018. Coordinated Reform and Local Solutions: Transforming the University Systems of Reward and Professional Advancement. https://doi.org/10.5399/osu/1134.

Risien, Julie, and Martin Storksdieck. 2018. Unveiling Impact Identities: A Path for Connecting Science and Society. Integrative and Comparative Biology 58(1): 58-66.

Scearce, Diana. 2011. Catalyzing networks for social change: A funder's guide. Washington, DC: Grantmakers for Effective Organizations \& Monitor Institute.

Seo, Myeong-Gu, and Douglas W.E. Creed. 2002. Institutional contradictions, praxis, and institutional change: A dialectical perspective. Academy of Management Review 27(2): 222-247.

Stachowiak, Sara, and Lauren Gase. 2018. Does Collective Impact Really Matter? Eight findings from a recent study of collective impact initiatives including their effect on systems and pollution-level outcomes. Stanford Social Innovation Review (summer edition).

Star, Susan Leigh, and James Griesemer. 1989. Institutional ecology, 'translations', and boundary objects: amateurs and professionals on Berkeley's museum of vertebrate zoology. Social Studies of Science 19: 387-420.

Strasser, Tim, Joop de Kraker, and René Kemp. 2019. Developing the transformative capacity of social innovation through learning: A conceptual framework and research agenda for the roles of network leadership. Sustainability 11(5): 1304-1325.

Tsoukas, Haridimos, and Robert Chia. 2002. On organizational becoming: rethinking organizational change. Organization Science 13(5): 567-582.

Van de Ven, Andrew H., and Marshall Scott Poole. 2005. Alternative approaches for studying organizational change. Organizational Studies 26(9): 1377-1404.

Vandenberghe, Frédéric. 2005. The Archers. European Journal of Social Theory 8(2): 227-237.

Weber, Edward P., and Anne M. Khandemian. 2008. Managing collaborative processes: common practices, uncommon circumstances. Administration \& Society 40(50): 431-464.

Wenger, Etienne. 1998. Communities of Practice: Learning, Meaning, and Identity. Cambridge, U.K.: Cambridge University Press.

Wenger-Trayner, Etienne, and Beverly Wenger-Trayner. 2015. Learning in landscapes of practice. In Learning in Landscapes of Practice: Boundaries, Identity, and Knowledgeability in Practicebased Learning, eds. E. Wenger-Trayner, M. Fenton O’Creevey, S. Hutchinson, C. Kubiak, B. Wenger-Trayner,13-29. New York, NY: Routledge.

Publisher's Note Springer Nature remains neutral with regard to jurisdictional claims in published maps and institutional affiliations.

Julie Risien is Associate Director of the Oregon State University STEM Research Center and Graduate faculty in Environmental Sciences and Marine Resource Management in the College of Earth, Ocean, and Atmospheric Sciences. Julie focuses on systemic approaches to transformation in social-educational systems to improve connections between the spheres of science and society.

Bruce Evan Goldstein is Associate Professor of Environmental Design at the University of Colorado Boulder. Bruce focuses on how learning networks catalyze changes in durable institutions that must adjust when social and ecological thresholds are exceeded. 